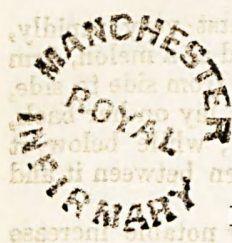

EDINBURGH OBSTETRICAL SOCIETY.

SFSSION XII.

\section{MEDICAL NEWS.}

\title{
坊art fouth.
}

OVARIAN DISEASF.

Rupture of Ovarian Cyst during Pregnancr-Recovery.-The following particulars of a case of accidental rupture of an ovarian cyst occurring during pregnancy, and followed by spontaneous cure, was read from Dr Gibson of Dundee :-

Mrs L._- a lady of very delicate constitution, and the mother of two children, but who, previous to my becoming her medical attendant, had miscarried repeatedly, and undergone at different times a long course of treatment by an eminent practitioner in one of our metropolitan cities, on account of chronic inflammatory ulceration of the uterine neck, aborted again on the 27 th July 1849, at the ninth or tenth week of pregnancy, and had flooded profusely before I could reach her residence some miles off in the country.

I found reason for believing this abortion to have been the result, like the others, of a renewal of the same chronic inflammatory mischief as formerly, and had accordingly to subject her to the appropriate treatment for some length of time ere I had the satisfaction of seeing her restored to a fair measure of health and exemption from suffering. One very profuse menstruation which meanwhile occurred at the end of seven weeks from the time she miscarried, having appeared very materially to contribute to the relief of her uterine state, and to hasten on her amendment. When, in the month of October, and just at the period when the catamenia should again have made their appearance, she was suddenly seized, after a walk that fatigued her, with violent pain in the lower part of the back, affecting chiefly the left side at first, but soon stretching round to both hips, and attended with intense sickness at stomach and harassing frequency of calls to make water. After three or four days of this suffering, she found the abdomen had suddenly become enlarged at its lower part, presenting a tolerably firm round tumour of about the size of an orange, situated towards the left iliac region, and sufficiently movable to admit of its being displaced and pushed about to a certain extent.

On the 30th of October, that is, fifteen or sixteen days after all this had commenced, I was requested by her husband for the first time to see her, the pain, nausea, and irritability of stomach having been meanwhile incessant. I then found that the tumour had increased in volume to about the size of a fist, was perfectly smooth on its surface, and of a well-defined globular form, still inclined towards the left iliac region, but realily movable; tender on pressure, which at the same time aggravated the pain and nausea, and attended with a constant distressing sense of internal stretching, distension, and weight.

Altogether it appeared to me to be an ovarian enlargement of one kind or another, though the suddenness of its origin, and the symptoms attending it seemed at the moment opposed to that view ; while my patient's own conviction was strong of her pregnancy, in spite of the entire novelty of her feelings and sufferings, and whatever the tumour might be.

Nor did a careful vaginal examination at this period throw much light on the matter, though I found the body of the uterus somewhat enlarged, the cervix elongated and somewhat voluminous, and the os so open as readily to admit the point of the finger, while they were all very tender on pressure. 
Only the fear of her pregnancy, to which the absence of the catamenia imparted some likelihood, deterred me from using the uterine sound.

By the end of November the tumour had attained, at first very rapidly, latterly more slowly, at least the size of two fists; was round as a melon, firm but somewhat elastic to the feel, and still perfectly movable from side to side, though it generally occupied exactly the mesial line as she lay on her back, and ascended about an inch beyond the umbilicus above; while below, it admitted of the fingers being thrust deep into the abdomen between it and the pubis.

The uterus also by this time had itself undergone a very notable increase in volume, its firm, round fundus being now easily discovered to have risen to a level with the brim of the pelvis; while on a vaginal examination, the cervix and os were found situated considerably higher than formerly, and the body of the organ was felt to have expanded so much as nearly to fill up the cavity.

On the whole, the hitherto perplexing ambiguities of the case seemed to be now clearing up. The fact of my patient's pregnancy was becoming more and more probable; while it was scarcely possible to suppose the tumour to be any other than an ovarian cyst, which the symptoms gave too much reason to fear had inflamed and might be undergoing a process of slow suppuration.

Meanwhile, the patient herself was now miserably dejected in spirits, got almost no sleep, was tormented with thirst night and day, and an increasingly obstinate state of the bowels; while the pulse was generally small, soft, and feeble, and she was for the most part very chilly, with occasional very transient flushes of heat. But as she resolutely declined being farther subjected to treatment of one kind or another, and expressed her settled desire just to let things take their course, I now for some time in a great measure discontinued my professional visits, though I heard of her frequently, and, I confess, was under constant apprehension of the cyst sooner or later giving way into the abdominal cavity, and thus, as a matter of course, almost speedily causing her death.

Matters, nevertheless, continued essentially in the same state as before, till the beginning of February 1850, when all doubt of her pregnancy having, meanwhile, in due time been settled by the occurrence of quickening, $\mathrm{my}$ patient, in the act of suddenly starting up from the sofa, felt conscious of violently straining herself. The immediate effect of this was a great aggravation of all her previous suffering, which in a few hours reached a pitch of absolute agony, accompanied by extreme faintness and sickness at stomach. The following morning, however, her intense suffering abated, and that rather suddenly, when, from sheer exhaustion, she fell into a prolonged and sound sleep, from which she awoke much recruited, and in all respects better. It was now found that the tumour had quite disappeared, and that a great diminution had taken place in the size of the belly. Far, too, from any of the evils arising which I had dreaded so long, her health from this time improved very speedily, and she went on in comparative comfort till the 27 th of June, when I was summoned to attend her accouchement. Her labour proved perfectly easy and natural, and she gave birth to a very fine boy of the average size; not a trace being to be afterwards found of the tumour, nor a single untoward symptom occurring, while she had also so completely recruited her strength as to be able to continue nursing for the usual period.

Thus terminated what appears to me a case of very singular interest ; spontaneous cure and recovery taking place under circumstances so apparently desperate as the rupture of a large ovarian cyst into the abdominal cavity, and that during pregnancy. For while it will not be doubted, I think, that it was by sudden rupture that the tumour in this case disappeared-the only way of accounting, in fact, for what occurred in the beginning of February. I satisfied myself by the entire absence at the time or afterwards of any outward discharge, that it was into the sac of the peritoneum it had emptied 
itself, and not by venting its contents into any of the natural outlets with which the walls of the cyst might have contracted adhesions.

Rupture of Inflamed Ovarian Cyst after Delivery-Death.-Dr $J . A$. Sidey reported the following case :-

Mrs Niven, aged 36, mother of five children, had always enjoyed good health, but was of spare habit, was struck or kicked by her husband on the right side a little above the pelvis, on the 28th of October. She was then seven months pregnant. At the time of the injury she felt sick and faintish, but was sufficiently well to give evidence in court against her husband, who was sent to jail for fourteen days. Sickness and fainting recurred three or four times a day until the 1st of November, when I was sent for. I then found her labouring under symptoms of shock, she was pale, cold, and almost pulseless, and fainting on the slightest exertion. She also complained of severe pain in the right iliac region, which bore the marks of a severe contusion. She required the free use of stimulants before she was able to bear the application of leeches and a blister, which so relieved her that she was enabled to go about her usual duties in a week.

On December 29 th she was delivered of a son, being attended by Mr D. Stewart. The labour was natural, and nothing abnormal discovered at the time. She progressed favourably up to Friday, $3 \mathrm{~d}$ of January 1853, when she was seized with shivering and slight symptoms, accompanied with pains in lower part of abdomen. These were relieved next day by the use of turpentine poultices and Dover's powder.

She, however, remained in bed until Saturday $10 \mathrm{th}$, night, when she rose. After sitting about ten minutes, she felt sick, and went to bed, when she was seized with very profuse hemorrhage from the uterus. She fainted several times, and became quite blanched. The hemorrhage was subdued by the use of Gallic acid and ergot, and the employment of cold cloths to pudenda. On Tuesday night it was completely restrained. She gradually improved until Friday 16th, night, when she rose and made her bed herself, walking barefooted over a stone floor. She had scarcely got to bed when she was again seized with shivering, followed by a profuse cold sweating. Next morning when I saw her, in company with Dr G. Weir, she complained of pain in left side, and over the region of the uterus. The pain was much increased on pressure, especially on touching the upper part of a tumour of about the size of the fist, and which was situated directly behind the symphisis, rising about an inch above it, and supposed to be the uterus. On a vaginal examination, the os was slightly open, and felt velvety. On the right side of the os there was a hard tense swelling like the end of an egg. Tongue white, furred, and moist. Bowels had been moved. No dysuria. Pulse 90.

She was ordered a blister, to be applied over the tumour, and a diaphoretic mixture. In the evening she was again examined, when a swelling similar to that on the right was felt on the left side of the os, and also another joining the two lateral swellings passing in front of the cervix. She was then ordered Mas. Pil. Hydrarg. iij., Pulv. Opii. gr. i., every three hours.

18th.- In the morning she was much in the same state, the pain continuing, but not so severe. She was then ordered to have eight leeches applied to the anus. In the evening there was a tendency to tympanitis and dysuria; in other respects, the same. She was ordered a turpentine and oil enema.

19th, Morning.-Has had rather a restless night, bowels have not been freely moved, still a good deal of tympanitis, and also frequent desire to make water. Ordered to continue the pills, and to have an assafotida injection. In the evening she complained of sudden and severe pain in pubic region, increased on pressure, and which was followed by symptoms of peritonitis. The pulse rose to 120 -small. She had an anxious look. There was a great deal of tympanitis, and slight vomiting. She was then ordered Cal. and Opii pills every two hours, and a blister over the pained part.

20th.-Tuesday and Wednesday she continued much in the same state; 
the bowels had never been freely moved, and the tympanitis and vomiting still continued. On Wednesday evening the pain suddenly left the pubic region, and removed upwards to the stomach. She complained of no pain except in that part. The tympanitis had disappeared in a great measure, but the vomiting had become stercoraceous. Dr Alison saw her, and she was then ordered ij. gr. Opii every two hours.

Thursday.-Passed a very restless night, and has had a good deal of same kind of vomiting, but without effort, the ejecta rising into her mouth. She is cold, and has a very anxious and sunken aspect. Pulse small, and scarcely to be felt. No pain except at stomach.

Died about half-past four.

Post-mortem forty-six hour's after death.-Present Drs Alison, Keiller, Pinkerton, and Sidey.

On opening the abdomen, all the intestines were found glued together by an effusion of recent lymph, the greatest quantity being about the stomach. In the pubic region, the upper parts of a dark gangrenous mass presented, partially covered with lymph. This tumour, which rose about an inch above the pubis, on examination was found to be the right ovary, which was impacted at the time, and occupied the whole of the pelvis, lying in front and above the uterus, and also pressing upon the bladder. On lifting up the ovary, which was slightly adherent, it was discovered to be twisted, so that it presented its posterior surface as the anterior surface of the tumour.

A quantity of thick bloody fluid escaped through a rugged and ulcerated opening situated on the posterior aspect and left side, as it lay in situ.

On removal, the tumour proved to be a multilocular ovary with the ruptured opening on its outer surface, two smaller openings were seen also. On cutting into one of the largest cysts, a clot of blood about the size of a walnut presented. The intermediate walls of the other cysts showed small points of ulceration. The uterus and left ovary presented a healthy appearance.

No other parts were examined.

Remarks. - The chief points of interest in this case are three in number, viz., 1st, The strong resemblance in symptoms and signs to a case of pelvic cellulitis, as manifested by the protracted convalescence after delivery, the paleness of the surface, the frequent rigors, followed by a feeling of bearing down, difficulty of defecation, and dysuria, and on examination, the presence of a tense painful tumour, with slight fluctuation, situated on both sides of the os uteri, and also crossing in front of it. Also a distinct tumour felt projecting: slightly above the pubis, and tender to the touch. These symptoms were such as fully to justify an opinion that the case was one of pelvic cellulitis. $2 \mathrm{~d}$, The position the ovary occupied in the pelvis and median line. The $3 \mathrm{~d}$, I think requires a good deal of consideration, and is interesting in regard to the medico-legal aspects of the case. But I shall merely resolve it into two questions. Did the blow cause the hemorrhage, followed by a subacute inflammation, and subsequent ulceration into the peritoneum? Or did the hemorrhage and inflammation take place spontaneously, as is often the case in ovarian tumours, results which might be promoted by the pressure necessarily exerted on such a large body by the contraction of the uterus and abdominal muscles during delivery?

Dr J. A. Sidey also stated the following particulars of two cases of rupture of ovarian cysts, occurring in his father's practice :-

RUPTURE OF INFLAMED OVARIAN CYST. - DEATH.

Miss M., æt. 36 , in the year 1840 , for the first time observed a tumour in the right iliac region, which on examination proved to be ovarian. The tumour gradually increased, and she had several attacks of pelvis inflammation, followed by phlegmasia dolens of the right leg. In 1841 the tumour became very large and the breathing oppressed. Diuretics and blisters were

NEW SERIES.-NO. LIII. MAY 1854. 
extensively used, without any marked effect. On the 20th of June she was tapped, and about five gallons of a viscid fluid drawn off. No untoward symptoms were manifested, and her health became much improved. But the fluid soon accumulated, and in about a month afterwards she was again tapped, and two and a half gallons drawn off. Within twenty-four hours a violent rigor followed, accompanied with pain in abdomen; pulse 120. There was also great tension of the abdomen and romiting. These symptoms continued for several days, but were at length removed. The sac filled again, and in three weeks after the second operation, the opening ulcerated and burst, and about three gallons of a limpid fluid was discharged, and also about ten ounces of pure pus. During August she improved very much, but on the 6th of September both orifices made by the trocar burst, and about the same quantity of pus, of a slightly blue colour, was discharged. At this time she became very weak, and tongue and fauces red and apthous. She, however, gradually improved with the free use of stimulants, and was able to sit up in bed. On the $22 \mathrm{~d}$ there was again a discharge of pus through the wounds, amounting to about one-gallon and a half. On the 25th of October there was another discharge of pus, and continued to discharge for several months about ten or twelve ounces daily, generally of pus, but sometimes of a clear fluid. Her health improved notwithstanding, so that on January 1842, she was able to sit up for several hours and sew-the tumour at the time being about the size of a small cocoa-nut. On the 7 th of February, after eating a hearty dinner, she was seized with intense abdominal pain and vomiting, and died in a few hours.

On examination it was found that the contents of the multilocular ovary, in a state of inflammation and ulceration, had been discharged into the abdomen.

\section{RUPTURE OF OVARIAN CYST.-RECOVERY.}

A lady, æt. 55, with the exception of dyspeptic symptoms, always enjoyed good health.

In September 1848, she experienced a sensation of weight in the left iliac region, and then, for the first time, observed a fulness there. Upon examination it was found to be the left ovary enlarged to about the size of a hen's egg ; the limb on the same side varicose.

The tumour rapidly increased in size, passing over to the right side, and at length ascending rather above the umbilicus.

Shortly after it had attained this size, while driving in a carriage over a rough road, she suddenly became faint and sick, and a feeling of coldness over the whole body followed. The ovary had evidently burst, as the tumour had disappeared, and the lumbar regions, as she lay on her back, were found on percussion to be filled with fluid. Violent abdominal symptoms, and a tympanitic state of the bowels came on; but these were subdued by hot turpentine poultices, and the fluid afterwards carried off by smart purging with pulv. jalap co. The varicose and swollen condition of the limb also disappeared. The enlarged state of the abdomen gradually subsided, and allowed the ovarian sac easily to be felt in the left iliac region. Health returned, and she was able to go about as usual. In December the ovary began to enlarge again; and in March 1849, it had attained the same size as before. Upon stooping down for the purpose of tying her boots, she, on a sudden felt very uncomfortable, as if " something had given way within her," and was immediately seized with violent pain in the back, and tympanitic state of the abdomen. Violent abdominal symptoms soon came on, and upon examination the tumour was gone. The treatment consisted in the turpentine fomentations, and jalap purges kept up for some time, and afterwards she was put under alterative doses of blue pill.

On the 1st of April, indications of the tumour enlarging again, became manifest; several blisters were applied, and various diuretics were used, without any marked benefit. About the beginning of May it had become as large as before, and burst the third time with a noise similar to a person emptying a 
bottle. This was followed by great depression and rigors; the breathing much oppressed, and countenance almost livid, the pulse very weak, requiring the use of stimulants. Abdominal symptoms then came on, which were again subdued with turpentine fomentations, large quantities of dark liquid stools followed the free use of purgatives. After the violence of the symptoms had been overcome, a strong bandage and thick compress were applied over the situation of the ovary, and was continued for several months. She again regained her health, and on examination seventeen months afterwards, only a very slight fulness in left side could be detected. She lately died from disease of the lungs, but on no occasion was there any greater fulness of the ovary detected. No post-mortem examination permitted.

The relating of these cases of ovarian disease, led to a lengthened conversation on the character of ovarian tumours, and on the various modes of treatment proposed by authors.

Dr Weir referred to a case of ruptured ovarian cyst without bad consequences that he had treated by large drastic purgatives. After the rupture, the cyst again enlarged and became the seat of acute inflammation, which resulted in a complete cure of the dropsy.

Drs Simpson and Moir also referred to cases of rupture of ovarian cyst occurring under their care.

Dr Keiller directed the attention of the Society to a case of parturition in a patient who had previously undergone the operation of ovariotomy.

\section{ON THE TREATMENT OF OVARIAN DROPSY BY INJECTIONS OF IODINE INTO THE}

CYSTS. BY PROFESSOR SIMPSON.

It has been often proposed to treat dropsy of the ovary upon the same principles as hydrocele or dropsy of the tunica vaginalis. In accordance with this view, Drs Hamilton, Scudamore, and others, have in former times injected ovarian cysts with irritating solutions of sulphate of zinc, etc.; but the results have in general proved so unfortunate and disastrous as to prevent a repetition of the practice.

In 1832, Mr Martin first recommended the use of tincture of iodine as the surest and safest injection for the cure of hydrocele; and this drug seems now almost universally adopted by surgeons in the obliterative treatment of this variety of local dropsy in the male subject.

Latterly, various surgeons, particularly Velpeau, Bonnet, Belluerimi, etc., have extended the practice of iodine injections to the treatment of other local dropsies and cysts; to chronic abscesses; diseases of the joints, etc. And the past experience of surgeons on the subject would certainly seem to show that while the local and direct application of iodine to morbid secreting surfaces has a great power of modifying, altering, and arresting even the secretory action of these surfaces, and often changes suppurative into adhesive inflammation, it shows at the same time wonderfully little aptitude to excite any excess of local irritation and pain. Hence naturally arose the question whether it could be safely and successfully injected into such large cysts as those of the common form of dropsical ovary.

In 1846, Dr Alison, of Indiana, recorded the history of a chronic case of ovarian dropsy that had been repeatedly tapped, and which he injected at last with a solution of iodine. Severe symptoms followed, but the ultimate result seems to have been favourable. In 1851, Dr Simpson assisted Mr. Syme in injecting a cyst in the neighbourhood of the ovaries, but not a common cystic form ovary. The symptoms which ensued were those of considerable excitement; but the original cyst apparently became obliterated. Another one in its vicinity has lately shown itself in this patient.

Within the last year, Dr Simpson has, subsequently to tapping, injected into dropsical ovarian cysts the tincture of iodine in seven or eight cases. For this purpose he has employed the common tincture of iodine of the Edinburgh Pharmacopeia, undiluted. He has usually thrown into the cyst two or three 
ounces of the tincture. In some cases he has allowed a portion of the injected fluid to re-escape; in others has retained the whole of it in the sac of the cyst that was tapped. From these cases he drew the following conclusions:-

1. In none of the cases of ovarian dropsy treated with iodine injections after tapping has he yet seen any considerable amount of local pain follow the injection, with one exception ; in most instances no pain at all is felt ; and in none has constitutional irritation or fever ensued. In the one exceptional case considerable local irritation followed; and the pulse rose to 110 ; but the same phenomena occurred in the same patient after previous tappings without iodine being used.

2. While the practice seems thus so far perfectly safe in itself, it has by no means proved always as successful, as in hydrocele in preventing a reaccumulation of the dropsical fluid; for in several instances the effusion into the sac seems to have gone on as rapidly as after a simple tapping without iodine injection.

3. But, in two or three of the cases, the iodine injection appears to have quite arrested, for the time being, the progress of the disease, and to have produced obliteration of the tapped cyst, as there is no sign whatever of any reaccumulation, though several months have now elapsed since the date of the operation.

Lastly. Accumulated experience will be required to point out more precisely the special varieties of ovarian dropsy most likely to benefit from iodine injections, the proper times of operating, the quantities of the tincture to be injected, and other correlative points. Perhaps the want of success in some cases has arisen from an insufficient quantity of iodine being used, and from the whole interior of the cyst not being touched by it. The greatest advantage would of course be expected from it in the rare form of unilocular ovarian cysts. In the common compound cyst the largest or most preponderating cyst is usually alone opened in paracentesis; and though it were obliterated, it would not necessarily prevent some of the other smaller cysts from afterwards enlarging and developing into the usual aggravated form of the disease.

Numerous Fissures in the Peritoneal Covering of the Uterus.-Death $6 \frac{1}{2}$ Hours after Labour.-Dr C. Skae related the following case :-About eleven o'clock A.M. on Saturday the 8th of May 1852, I was requested to visit Mrs S. in her seventh confinement, symptoms of labour having come on two hours previously, attended with flooding. On examination, the os uteri was found scarcely at all dilated, and the hemorrhage had almost ceased. The pilul plumbi opiat was administered, and cold applications directed to be applied externally, in case of any return of flooding. On again visiting, at about halfpast three p.M., the os was found dilated to the extent of a crown-piece, pains brisk, with a mere show of coloured discharge. After rupturing the membranes, a dose of the liquor secal was given, and increased uterine action speedily followed. Labour went on steadily till half-past seven P.м., when a dead foetus was expelled, and the placenta was thrown off without any extractive interference, or any amount of coagula beyond what is usually met with. About half an hour afterwards, while conversing with her husband in his garden, the nurse sent to say that Mrs S. was flooding. On undoing the binder, the uterus was found somewhat relaxed, and some eight ounces of coagula were found to have been expelled. The uterus was kept steadily compressed, a dose of the ergot of rye given, and an ounce or two of brandy, as the circulation was feeble, and the countenance indicated considerable prostration of the vital powers. From this time there was no return of hemorrhage, and the uterus continued well contracted; still, the countenance and circulation indicated an increasing loss of strength, notwithstanding the repeated exhibition of stimuli at short intervals. About half-past nine P.M., I became apprehensive of her safety, and speedily had the assistance of Drs Zeigler. An opiate was administered, and other means used calculated to obviate the rapid ten- 
dency to sinking, which now became painfully evident, but with scarcely any benefit. About eleven P.M., Dr Simpson, with the assistance of Mr Carmichael, transfused from the arm of a stout maid-servant some five or six ounces of blood, but with scarcely any appreciable effect. The circulation steadily declined, and she sunk at two o'clock A.M. on Sunday morning, six hours and a half after delivery.

On examining the placenta, it was found that a segment of it had been separated from the uterus during labour, which was sufficient to account for the accidental hemorrhage, the total amount of which, from first to last, could not have exceeded fifteen to eighteen ounces.

The urine was examined, and found slightly albuminous.

Autopsy. - Some four or five ounces of extravasated blood were found in the peritoneal cavity, and both broad ligaments had an ecchymosed appearance. The anterior surface of the uterus exhibited some twenty-five or thirty fissures of an oblique irregular appearance, extending merely through its peritoneal investment, varying from three to six or eight lines in length. No other notable morbid appearances were found, with the exception of slight fatty degeneration of the kidneys.

A conversation ensued on cases of death post-partum, from hemorrhage, placenta-previa, etc.

New Vaccinator.-Dr J. Struthers exhibited a vaccine scarificator which he had received from Dr Marcus, a surgeon in the Danish navy, and which had been invented by Professor Dryer of Copenhagen. In form it resembles the iron pen, with two legs and screw for regulating their distance, commonly contained in cases of philosophical instruments ; but the extremities of the legs, instead of being pointed, are broad and sharp, similar to those of the double knife of Valentin. The advantages of this instrument are-1st, That the scarification and vaccination are effected by one application of it. The point, previously dipped in lymph, being simply drawn over the skin, scratching it to the required depth ; and $2 \mathrm{~d}$, The rapidity with which a number of individuals can be vaccinated at a time; the quantity of lymph capable of being held between the blades, being sufficient for 20 or 30 applications. This instrument is extensively used in Denmark, where the practice of revaccination is general, and is almost the only one employed by the army and navy surgeons, who consider it superior to those in use in this country. Dr Marcus also informed Dr S., that in Denmark the practice of preserving the vaccine lymph, in capillary tubes, has been general for several years past.

Uninterrupted Series of Preternatural Labour in the same WoMAN.-Dr Pattison related the particulars of an uninterrupted series of preternatural labour occurring in the same female. The woman had given birth to five children, four of which presented by the feet, and one by the breech. Nothing remarkable in her conformation was observed, nor were there any other circumstances known that could account for her children always presenting by their pelvic extremity.

Dr P.'s case led to a conversation on the position of the child in utero, and the probable causes of malpresentation. The opinions of Nægalê, and others, as to the effect of early irregular uterine contraction, in determining the presentation, were referred to. Dr Simpson stated that, whatever be the true explanation of preternatural presentation, he believed that the child always adopted that position in utero, which was freest from irritation, and that peculiar shapes of the uterus, from congenital conformation, or otherwise, might thus act in producing corresponding irregularities in the position of the child. In this way, he believed that the malpresentations which are sometimes observed to occur in members of the same family, may be explained, peculiar shapes of the uterus being probably influenced and determined by family predispositions, as much as peculiar shapes of other organs are.-Cases of malpresentations occurring in members of the same family were related by 
various members, which tended to establish predisposition as a probable occasional cause of preternatural labour.

Illustrative cases were cited by Dr Keiller, Dr M`Cowan, Dr Malcolm, and Dr Simpson.

\section{MEDICO-CHIRURGICAL SOCIETY OF EDINBURGH.}

\section{Session xxxiri., 1853-54.}

\section{March 1, 1854.-J. Y. Simpson, M.D., President, in the Chair.}

On Excision of the Knee-Joint. By R. J. Mackenzie, F.R.C.S.-Mr Mackenzie said that he had now performed this operation in three cases. The first would be immediately presented to the Society, and would speak for itself. Recovery in the second case had, from various causes, proved more tedious than it had at first promised to be. The patient, however, progressed satisfactorily, though slowly; and Mr Mackenzie had no fear as to the ultimate result. The limb was becoming rigid at the knee, and was straight, shapely, and but moderately shortened. He hoped at a future meeting to present this patient, with a sound and serviceable limb. In the third (a peculiarly unfavourable case for the operation), the result had been fatal. The case was one of acute ulceration of the cartilages, accompanied by suppuration; the joint being distended with pus. The patient, a lad of 18, was in an advanced stage of hectic, emaciated, and much exhausted by continued suffering. He was most reluctant to submit to amputation; and, having seen one of the patients walking about, on whom the operation of excision of the knee-joint had been performed, he expressed an anxious wish that an attempt should be made to save the limb by the performance of this operation. It was a matter of regret that this request had been complied with; for, although amputation held out but a small chance of recovery, the case was little suited to test the merits of the operation of excision. Immediate and great relief followed the operation; and, as far as the limb was concerned, everything had progressed as favourably as could have been wished. Diarrhœa, however, which had been threatened before the performance of the operation, set in; the tongue and lips became covered with aphthous crusts; he suffered from cough and night sweats; and sank, in the course of a month after the operation. The wound was in great part healed, and no difficulty had been experienced in keeping the limb in excellent position. Permission could not be obtained to examine the body ; but Mr Mackenzie had little doubt that tubercular disease of internal organs would have been found.

Mr Mackenzie stated that, since the subject had been last brought before the attention of the Society, the operation had been performed by several able surgeons in England, Scotland, and Ireland. He had written to four of these gentlemen, requesting them to furnish him with the result of their experience; and he had received from all very kind and full replies to his inquiries. He read some extracts from the letters which he had received from $\mathrm{Mr}$ Page of Carlisle, Mr Gore of Bath, Dr Keith of Aberdeen, and Mr Butcher of Dublin, all of which gave favourable accounts of the cases under their care, and expressed themselves as being advocates of the operation.

A patient (a man between forty and fifty years of age), was then exhibited, in whom $\mathrm{Mr}$ Mackenzie had performed the operation of excision of the kneejoint a year previously. He appeared to be in robust health, and traversed the hall, in various directions, with ease and celerity. In walking, the toes were pointed downwards, but, his body yielding slightly, he planted the foot firmly on the ground, and rested his entire weight on the limb without uneasiness. In the horizontal posture, he elevated and depressed it with the greatest nicety. On examination, the limb was found slightly curved outwards, firmly anchylosed at the knee, three quarters of an inch shorter than its fellow, and equal in muscular development. The heel of the shoe was raised inside three-fourths 
of an inch, to allow for the shortening. He stated that he had been walking for six months.

Mr Syme said, that the question was not as to the possibility of saving the limb, but how far excision of the knee-joint could be substituted for amputation of the thigh, and an useful limb preserved. Now, all subsequent experience went to show that the operation was not a good one, and that it could not with advantage be substituted for amputation, even admitting the possibility of keeping on the limb. He questioned the usefulness of the limb in the case shown to the Society. The future must be looked to ; and much depended on the avocations of the patient. Should they be rough and laborious, the limb would speedily be affected with swelling or ulcerations, and amputation would become necessary. Again, how many times have the limbs been lost, or unsatisfactory results obtained? The question was not Mr. Mackenzie's skill as an operator; but how far we could regard this operation as a boon to the human race.

$\operatorname{Mr}$ Mackenzie was sorry to hear the statements of Mr Syme, which he could not but regard as the results of mere theory, and not deduced from a fair consideration of the facts which had been brought forward. He would only refer to the opinions of some of the best surgeons in the country, whose recent experience of the operation bore ample testimony to its value, as shown in the letters which he had read to the Society. Mr Syme had spoken of the great loss of life following the operation. In this $\mathrm{Mr}$ Syme was mistaken; of the last fifteen cases in which the operation had been performed, three cases only had terminated fatally; a proportion which would surely bear comparison with the operation which Mr Syme recommended, amputation of the thigh. Mr Syme, too, spoke of the useless limbs which were preserved. He would refer to the patient whom they had just seen, and would leave the Society to judge whether his limb were useless; he would refer to such cases as that of Mr Page, where the patient was standing or moving about at his employment the whole day, sometimes walked six or seven miles to the country for his amusement, and could walk with any of his companions. He would refer, indeed, to the gratifying results in this respect of nearly every case in which the operation had been performed of late years. With scarcely an exception, the operation had been the means of saving a truly serviceable limb.

Mr Syme did not expect to change Mr Mackenzie's opinions. The object of his remarks was to state his own; and a little time would show which were correct. He might be wrong in the conclusions to which he had come; but he begged to adere to them. EsQ.

On Velo-Synthesis, or the Operation for Cheft Palate. By James Syme,

Mr Spence differed from Mr Syme as to Mr Fergusson's plan of operation being impracticable. Some years ago he had assisted a friend in performing the operation according to that plan, and no difficulty was experienced in keeping the parts tense during the section of the muscular fibres. The knife used on that occasion was one made after the pattern represented in Mr Fergusson's work. From what he saw at that time, he felt doubtful whether the levator palati could be divided by a knife so short in the blade; and he had subsequently made several experiments and dissections to satisfy himself on that point. He found that though with the knife in question the muscle could only be partially divided, complete section could be accomplished with ease and certainty by a knife a little longer in the blade. The palato-glossus and palatopharyngeus, he believed, could scarcely be completely divided with safety or certainty. The most doubtful point to him was, whether the horizontal division or splitting of the soft palate, necessary to effect section of the levator palati, might not sometimes interfere with the vitality of the part, and so prevent union.

Mr Mackenzie could entertain no doubt as to the possibility of entirely dividing the levator palati, which was the principal desideratum in Mr 
Fergusson's operation. As he understood Mr Fergusson's method, it was not generally necessary to divide more than the anterior fibres of the palatopharyngeus, whilst the palato-glossus rarely required to be interfered with at all. With regard to the results of Mr Fergusson's operation, which had been described by $\mathrm{Mr}$ Syme as such a useless and improper proceeding, he ( $\mathrm{Mr}$ Mackenzie) had lately learnt on inquiry, that Mr Fergusson had performed the operation in thirty-three cases, and that with one or two exceptions, the results had been nearly perfect.

Mr Syme objected to the interpretation Mr Mackenzie had put upon what he had said. His (Mr Syme's) remarks only went to show that the palatal muscles need not be divided to ensure good results in the operation; but he had no wish to throw any doubt on the amount of success claimed by $\mathrm{Mr}$ Fergusson.

Dr James Johnston, when in Canada, had assisted Dr Home, an army surgeon, in performing the operation for velo-synthesis, as recommended by $\mathrm{Mr}$ Syme. No muscles had been divided; and a successful result followed.

On the Weight and Specific Gravity of the Brain in Insanity. By Daivd Srat, M.D.-This paper will be published at length in a future number.

On the President asking for any medical news-

Cardiac Disfase.-Dr. Bennett said that there was in the medical clinical ward of the Royal Infirmary, a case in which all the signs of disease of the valves of the pulmonary artery, hypothetically laid down by the late Dr Hope (who had, however, never met with a case), were present.

Mortality from Measzes. - The President said that during the present epidemic of measles, it had been remarked that no deaths had taken place at its commencement, but that latterly some fatal cases had occurred. The Society would be glad to hear from any member what the patients had died of. $\mathrm{He}$ stated that he had himself seen three or four of the fatal cases. In one death was caused by sloughing of the throat, resembling noma, and such as had been described by $\mathrm{Dr}$ West of London. In another there were pneumonia and pleurisy and peritonitis, with indeed general inflammation of almost every internal organ. Of other two cases the first had not been recovering satisfactorily, when symptoms presented themselves which were attributed to hydrocephalus, but rapidly became tetanic, and she died of tenanus next night, having been ill about forty hours. On post mortem examination, one large and several miliary tubercles were found in the brain. The second case, which occurred shortly after the former, and what was remarkable, in the practice of the same gentleman, had passed through the measles so easily as to require nothing in the shape of drugs to be prescribed. Tetanic convulsions suddenly supervened; they were the most severe that Dr Skae had ever witnessed. The patient died in thirty hours. On examination after death no lesion could be found. There had been ischuria from the commencement of the attack of convulsions, and no urine could be obtained for examination. The bladder was found empty.

Hysterical Spasmodic Cough.-Dr Andrew Wood said that about a fortnight ago, in a public institution for the education of girls, one of the inmates was seized with a peculiar spasmodic cough, coming on in paroxysms every half hour or twenty minutes, and for some time he was at a loss; but others of the girls becoming affected, Dr. Wood recognized an old friend, which had come under his notice in a kindred establishment about two years ago. About a dozen of the inmates were then affected, and on coughing made a sound resembling the cry of a turkey-cock. No remedy seemed to check the complaint, except removing those affected to their homes. In one case, where from the violence of the symptom the larynx was feared for, chloroform, then but newly introduced, had an admirable effect. In the present instance only three or four cases have occurred, those affected having been removed to separate houses,-an opiate usually completing the cure. 
April 5, 1854.-J. Y. Simpson, M.D., President, in the chair.

CASE OF HYSTERIA AND SPURIOUS PREGNANCY. BY DR KEILLER.

THIs case, an abstract of which appeared in the Journal for 1849-50, in the proceedings of the Obstetric Society of Edinburgh for March 1850, was given in great detail. The patient, an hysterical young woman, was supposed by her friends to be in the family way, from the large size of the abdomen, and the occurrence of pain, which elicited such loud cries that the whole neighbourhood was disturbed. Her supposed labour continued for many weeks, and Cæsarean section was proposed, as a last resource, by an irregular practitioner. When Dr Keiller saw her, and made a careful examination, he attempted but in vain to disabuse of the minds of her relations that she was pregnant. A variety of treatment was instituted, but without any marked benefit; indeed, change of air was the only thing that seemed to do her any good. After one of these removals, she was able to return for a short time to her usual employment at a mill, though her abdomen always remained of a large size. Dr Keiller lost sight of her till eight years after she presented herself in Edinburgh, with a child that she had had in the interval, complaining that her old symptoms were reappearing. Her abdomen was very large and tympanitic. She was sent into the Maternity, where, with the advice of Dr Simpson, she was put under the influence of chloroform. The abdomen immediately became flat, and the uterus was felt to be of its normal size. When the effects of the chloroform passed off, however, the abdomen again enlarged in size, and resumed its former bulk. During her stay in hospital, she introduced foreign matters into her urine, which on one occasion presented a dark colour, as if from the admixture of ink, for, on the catheter being passed, limpid urine was drawn off. She left the Maternity, and, when last heard of, was still suffering from her obscure complaint. Dr Keiller stated that a somewhat similar case, though not complicated with the symptoms of pregnancy, was at. present under his care in the Hospital, in which chloroform had the same effect in removing the distension, and galvanism was similarly serviceable.

Dr W. T. Gairdner had perused an essay lately published by Mr More O'Ferral of Dublin, on Abdominal Tympany, in which a similar observation on the use of chloroform in the diagnosis of such cases was made, but with no mention of the previous investigations of Dr Simpson. It was interesting, however, to find a collateral and independent testimony to the value of the agent.

The President said, that his own observations on the use of chloroform in the diagnosis of such cases would be found in the same journal, at least three or four years before the appearance of $\mathrm{Mr}$ O'Ferral's paper. He believed that cases of spurious pregnancy were often met with in practice; for many a married lady would acknowledge, when questioned, that she had once or twice thought herself pregnant, when, as the result showed, she was not. He had, in his own practice, seen several cases in which ladies had removed into town with their entire establishments, in the full belief of their approaching confinement, and where he had had the disagreeable duty of informing them that they were not in the fanily way. These were instances in which patients progressed onwards to near the full term of pregnancy, suffering all the usual symptoms and discomforts of that state. Sometimes phenomena exactly like those of labour came on at the full term. This seemed to have occurred in Dr Keiller's patient. Dr Simpson had seen several analogous instances of spurious pregnancy terminating in spurious parturition. Besides the cases of pseudo-pregnancy, in which the patient went on with the usual symptoms of pregnancy till near or up to the full period of labour, there were other varieties of this curious morbid state. In some, for example, the affection lasted only for a few months; in others, they occasionally continued far beyond nine months, and became, as it were, chronic in their character. As to the symptoms themselves, they consisted of the presence of more or fewer of all the

NEW SERIES.-NO. LIII. MAY 1854. 
usual sympathetic symptoms of pregnancy, as swelling of the abdomen, nausea, and sickness, a feeling of quickening and motion of the child, etc. Dr Keiller had stated that the mammary signs were not well marked in his patient. Sometimes, however, they were ; and he (Dr Simpson) had sketches illustrative of this fact, executed by the patient herself during a state of spurious pregnancy, and in whom, in a subsequent veritable pregnancy, her first, the areolæ did not present a deeper tint than they had done during her pseudopregnancy. As to the sensations which had been described in such cases, they were very frequent, and sometimes there were true motory contractions in the abdominal walls. Dr Simpson was inclined to believe that the malady was connected with the ovary. In one aggravated case which had fallen under his observation, there was marked ovaritis, and the ovary subsequently suppurated. Again, it was observed that, although menstruation did occur in the cases which had been noticed, yet it was much scantier than usual, and sometimes the catamenia were wanting for several months. It was well known that the complaint was not peculiar to the human female. Harvey had long ago remarked that, in hounds who were well fed, many of the phenomena of pregnancy, such as swelling of the abdomen, and the presence of milk in the mammæ, occurred both subsequently to unsuccessful sexual intercourse, and also frequently after seasons of heat, but during which there was no intercourse with the male: kittens and other young animals were frequently stolen by the animal, to make the semblance of a litter. The curious observation had also been made by Harvey, that the animals were liable to the diseases of bitches which had recently been delivered. He (Dr Simpson) believed that, when some of the cases of the so-called hysteria in unmarried females were inquired into, they would be found, as he thought he had repeatedly seen, to be really symptoms only of spurious pregnancy. Dr Keiller had alluded to the retraction of the limb as having been a well marked symptom in his patient. He (Dr Simpson) had seen a case many years before the introduction of chloroform, in which the symptom was a prominent one. The lady had been under treatment in Paris, and, on her return to Scotland, a surgeon examined her, and recognized, as he supposed, the presence of a large ovarian tumour - not an uncommon mistake, as, in the records of ovariotomy, six cases are detailed in which no tumour could be found after the abdomen was opened. Dr Simpson was consulted, and, on percussing, he found the abdomen quite tympanitic, and of course negatived the tapping, and the presence of any ovarian tumour. The leg in this case was much drawn up, and he was informed that, while in Paris, the heel was for a time closely applied to the back of the neck. With regard to the nature of the abdominal swelling in spurious pregnancy he had tried various experiments to ascertain its cause, but in vain ; and as yet he could come to no decided conclusion on the subject. It had been suggested that, while the patient was deeply under the influence of chloroform the contained air escaped unobserved ; but in one very marked case in the hospital, he had a tube passed per anum, its nozzle being kept under water ; but not a bubble of air escaped. The diaphragm he was inclined to suspect to be a chief agent in the production of the swelling. The chloroform, he believed acted by relieving the muscles, diaphragmatic and abdominal, from the influence of reflex action, and permitting their relaxation. Dr Keiller had classed the interesting case which he had communicated under the head of hysteria; but some of the cases to which he (Dr. Simpson) had alluded, could scarcely be properly included under that designation. The phenomena were common to the females of our domestic quadrupeds, and in them would not be designated hysteria. Dr Simpson suggested that a series of experiments should be made on the bitch during the occurrence of the anomalous pregnancy, to ascertain, by examination of the state of the ovaries and uterus, the true nature of the cause.

Dr Matthews Duncan had lately seen a case where the explanation of abdominal swelling was completely made out. A young lady had been long in 
bad health ; her chief symptoms were referrible to the left hypogastric region, which was very tender, dull on percussion, and extremely distended. Called in consultation, he recommended the production of deep anæsthesia as a diagnostic aid. Long before the girl was insensible, he remarked the great anterior arching of the lumbar vertebre, which, as insensibility came on, disappeared; the spine coming to touching the mattress, from which it was before far removed. At the same time (no doubt from relaxation of the diaphragm and anterior abdominal muscles) the abdominal distension disappeared and also the left iliac fulness, to the great relief of her anxious friends. $\mathrm{He}$ thought it very important to distinguish cases of spurious pregnancy from cases of false pregnancy. Real cases of the former disease were common in the lower animals, but, he thought, not very common in women. From these, where not only was there no deception, but the real existence of many of the signs of pregnancy, should be carefully separated cases of false pregnancy. These last were of various kinds. In some, the female simply wished to deceive, in others, she was herself simply deceived, easily undeceived, and the phenomena found were explicable without supposing spurious pregnancy. In a third class of false pregnancies, we had a good example of the so-called electro-biological state. The female's mind was impressed with the unshakeable conviction that she was pregnant, and under these circumstances some of the symptoms of pregnaney were induced.

The President had made some experiments on the subject in the wards of the hospital, and had satisfactorily ascertained that in the cases he had examined, the prominence of the abdomen did not depend upon any arching of the spine.

Dr Keiller concurred with Dr Simpson with reference to the agency of the spine. In the case at present under his care in the hospital, and to which he had alluded, particular attention had been paid to the position of the spine; and he could not detect any connection between it and the abdominal swelling. $\mathrm{He}$ believed, with $\mathrm{Dr}$ Simpson, that the peculiar appearance was mainly due to the action of the diaphragm, and he had observed that patients labouring under the disease could voluntarily increase the size of their abdomen by a little effort. Dr Montgomery of Dublin, in a note which he ( $\mathrm{Dr} K$.) had lately received, stated that he had seen a number of cases of the same kind, and that one somewhat similar to the one just read to the Society, was recorded in his book, On the Signs, etc., of Pregnancy, p. 173. Dr Montgomery went on to say, that the "whole subject was full of wonders, almost justifying. Harvey's strange idea that the conceptions of the brain and uterus were to a certain extent identical and might change places"!

\section{CASE OF RUPTURE OF THE HEUM. BY F. THOMPSON, M.D., OF PERTF.}

The patient was admitted into the Perth Infirmary with the symptoms of acute peritonitis, the effects of a blow which he had received on the groin about two hours before, from a piece of wood which was being cut by a circular saw, and which had started back. He gradually sank forty hours after the receipt of the injury. The pulse never rose above 70. On examination, the ileum was found ruptured in two places, the contents of the bowels had been extravasated, and the peritoneum presented the usual morbid appearances of acute inflammation. Very faint marks of violence were observed on the site of the blow, but extensive ecchymosis existed over the ribs of the same side, where no injury could be ascertained to have been received.

Dr W.T. Gairdner said that the case was important in a medico-legal point of view, as the question might be raised, Whether the openings in the bowel were the result of violence or of disease? It, however, admitted of a satisfactory answer. In apertures, the result of external violence, there was invariably eversion of the mucous coat of the intestine-a fact which was explained by the greater copiousness of that structure, and its lax connection with the serous layer. In apertures, however, which were produced by disease, though both layers were 
involved, the mucous membrane was destroyed to a much greater extent, and was not found everted. In the specimen which had just been handed round, there could be no doubt, from the appearance of the openings, that they had been produced by external violence.

Dr Matthews Duncan observed that, at first sight, it appeared difficult to understand why external violence should produce a circular opening, as if a piece had been punched clean out of the bowel. This was aptly explained by observing' the effect of a lineal incision in the uterine wall, in performing Cæasarean section. The effect of the incision was to make a circular opening, as had been remarked by Sir Charles Bell. In the same way, the opening of the bowel was by the contractions of the variously directed muscular fibres quickly changed from a lineal or irregular wound to a circular one; and thus the curious phenomenon might be explained.

The President asked Dr W. T. Gairdner if any explanation had as yet been given of the presence of two circular ulcers occasionally met with at the pyloric end of the stomach. He (Dr Simpson) had seen them occupying positions exactly opposite to each other, and in the line of the axis, which, according to physiologists, the bolus of food assumed at that portion of the stomach. These ulcers were generally met with in servant girls who had come into town from the country, and were subjected to a change of diet in the shape of a greater quantity of solid food. Indeed, one of the first items in their treatment was the substitution of liquid nourishment.

Dr W. T. Gairdner said, the difficulty was to explain the destruction of the mucous membrane ; but if we could suppose that it had suffered violence from something which had been swallowed, then, the mucous coat once through, he believed that the gastric juice would keep up a sufficient irritation to prevent the healing of the ulcer. Similar ulcers were sometimes, though rarely, found in the duodenum, but, as far as his observation went, never lower down.

\section{April 19, 1854.-J. Y. Simpson, M.D., President, in the Chair. \\ case of catalepsy. BY JOHN COLDSTREam, M.D.}

The case was detailed at great length; the following is a short abstract of its history. The patient was a lady, aged 29, of sanguine temperament. She had laboured some years before under lateral curvature of the spine, but her health continued good till 1852, when she was seized, while in the country, with the symptoms of simple fever, during the convalescence from which, she betrayed certain aberrations of intellect. She was brought into town for change of scene, and for some time she continued excited, capricious in her temper, and shunning society. In the course of the summer these symptoms disappeared, and in August she was in her usual state of health. Again, however, in September, she began to shun her friends, averting her eyes from persons who addressed her. During five months from October, she passed through many phases of mental complaints, and appeared disinclined to use her mental faculties. Prior to menstruation it was noticed that her head was hot and face flushed-symptoms, however, which were relieved by the flow. At this time she refused to speak, at times, for hours together : her silence was evidently voluntary. Her symptoms varied from time to time, but mental aberration was absent, though she was still suspicious of her strength of mind. In March 1853 , she began to be obstinate and complained of illness ; she appeared depressed, and her extremities were observed to be cold. A few days after she threw herself from bed on the floor, and on her physician being announced, declared that she would never speak to him again. She kept her word, but she was subsequently dumb to every one. She immediately became cataleptic. In April, the last phase of her disease made its appearance, and lasted till her death, which took place in the following September. There was catalepsy, extreme quiescence and rigidity, anæsthesia, and unwillingness to eat. She lay on her back, and seemed to be destitute of feeling and consciousness, except for one hour in the morning, when she busied herself at her toilette, but if any 
one entered she instantly became cataleptic, and remained so as long as the visitor was in the room. When any attempt was made to move her, her muscles instantly became rigid. Even the eyes and the auditory canal appeared to be in a state of anæsthesia. She never spoke but twice: once during the application of galvanism, and again a short time before death. No words addressed to her seemed to affect her, except on one or two occasions. Music had no effect upon her. Her attendants firmly believed, however, that she noticed all that passed around her. She slept regularly, muttered occasionally in her sleep, but there was no somnambulism. Her resistance to take food dated from the middle of April. The approach of the spoon to the mouth produced violent contractions of the muscles of the lips and jaws, the face becoming flushed during the struggle. For the sake of brevity, as the case was very protracted, Dr C. classed the description of the symptoms under several distinct heads. And, 1, As to the cataleptic symptoms. They were always readily manifested when she was awake; a rude touch (a slight one was ineffectual), or any attempts at passive motion sufficed to produce them. They could be overcome, however, by exertion on the part of the attendants. She could balance her body on one limb, and maintain the posture for several minutes. A weight of $10 \mathrm{lbs}$. could be suspended on the extended arm from the wrist without deflection; a little more added to the weight, however, sufficed to pull the arm down. (In the case recorded by Heberden, 7 lbs. attached to the hand proved sufficient to bend the arm). While in the horizontal position, she bore a weight equivalent to $12 \mathrm{lbs}$. on the lower limbs, when these were raised a short distance from the sofa. Uneasiness was only expressed by her on being made to assume for some time a half sitting posture, with the limbs placed horizontally. The eyelids were generally closed : on being touched, contraction of the orbicularis followed, but on force being used, the elevators became cataleptic. The eyes were directed upwards, and had a vacant expression ; the irides being more sluggish than natural. The symptoms were more pronounced in the after part of the day. The experiments that were made evidently induced fatigue, and on force being employed there were paleness of the face and quickening of the pulse. 2 . As to the Quiescence. As already stated, for one hour only in the day did she move about, at other times not a muscle moved. Indeed, her appearance of absolute stillness produced a feeling of awe in the beholder, and aimost induced the belief that we were looking upon a corpse. 3 . The Anæsthesia. It was difficult to ascertain its extent correctly, as no response was elicited by any stimulus, except when galvanism was applied, and food was attempted to be introduced into the mouth. The most tender parts of the body were pressed, etc., etc., were touched by flies, or pricked with pins, and no shrinking was produced; yet whenever an attempt to give food was made, violent movements took place. Noises, or nauseous substances in the mouth had no effect upon her, but she winced under a bright light. The resistance to food appeared to have no connection with the kind presented to her ; the gustatory nerves seemed as much affected as any other. The motions following the touch of the spoon showed that the lips were not anæsthetic ; yet they, along with the face, were frequently seen covered with flies without the slightest motion resulting. The application of hartshorn to the nose only produced a flow of tears. 4. Speechlessness; at first only the will was lost, and it might be attributed to hysteria, and afterwards she was ashamed of her taciturnity; but the silence that came on subsequently with the catalepsy began with her determination not to speak to her medical man, though she extended it to every one. During sleep she occasionally spoke; once during the action of the galvanic machine she called out "stop, stop," and when near death she faintly said "the sofa." 5. As to the resistance to the introduction of food. It was similar to what is observed in many cases of melancholia and mania. Even after emaciation had long existed, the attempt to feed her was attended with flushing of the face and a flow of tears, but the 
hands were never raised, or the head bent back in resistance. Food when once introduced into the mouth was seldom rejected, though it was swallowed slowly. Digestion seemed normal. The pulse became more quick as the atrophy progressed. There was no bruit at the heart, and the respiration was soft and slow, as if she were asleep. The urine was healthy, it was generally passed during the struggles at her meals. The catamenia appeared shortly after the first appearance of catalepsy, but not afterwards. Her temperature was low, and the extremities generally cold. Death took place by exhaustion six months after the first occurrence of the catalepsy: the muscles preserving their rigidity to the last. No post-mortem examination could be obtained.

As to the Causes.-The predisposing were present in her active, sensitive, and by no means robust frame. She had sustained a severe shock from the suicide of a young friend, about a year before her illness, but recovered from it sooner than had been anticipated. The friends conld see no connection between this and her subsequent illness, but the author thought it was not improbable that the shock sustained at that time was the remote cause. As to the treatment; he at first feared melancholia or mania, and hysteric symptoms were also present, but he felt hopeful as to the issue of the case, as the patient was originally of a strong intellect, and of a cheerful disposition of mind, and from time to time there were signs of improvement. After the catalepsy set in, the head especially was attended to, and blisters, followed by turpentine enemata, valerian, valerianate of zinc, aloes, musk, cod-liver oil, etc., and, subsequently, the inunction of olive oil were had recourse to. Electricity, gradually increased in strength, was tried, and after a time one wire was placed over the epigastrium, while the other was applied below the knee. Strong contractions of the abdominal muscles followed, the face was flushed, and the head raised from the pillow, while she cried out "Stop, stop." He was of opinion that she was rather injured than otherwise by the use of the galvanism, and the morning activity certainly lessened. Chloroform was administered on one or two occasions; she slept after it, with her mouth more open than usual.

In the present case he was inclined to believe that there was slight organic disease of the brain, the result of the nervous shock which had been sustained, and which in another individual might probably have produced mono-mania. A remarkable circumstance was the absence of any lengthened remissions, which made the case differ from the other cases on record. He could not regard the malady as feigned, as no motive was dicoverable for the production of the symptoms.

The President said that he had seen two examples of the disease; one in his student-days in the wards of the Royal Infirmary, under the care of Dr Duncan, jun., which came on with mental excitement; and the other in the City Lunatic Asylum, a few years ago, in which the symptoms were not so well marked. With regard to the interesting case which had just been read, he could corroborate what Dr C. had said as to the feeling of awe produced by the appearance of the poor patient. She was clothed in white, and as she lay on the sofa, in her great emaciation, with the stillness of a statue, she contrasted remarkably with her former self, as she was depicted in glowing colours in a picture which was suspended exactly opposite to her. This, with the stillness of the room, and the subdued manner of the attendants, all tended to form one of the most curious sights he had ever seen. He would be glad to hear from the members any new pathological views which might be current with regard to this strange malady. It had been proved by experiments with brucines and strychnine that symptoms resembling tetanus might be produced, but as far as he knew the peculiar symptoms of catalepsy could not be so obtained.

At the request of the President, Professor Macdougall, while quite unprepared, as he said, for the unexpected call, made a few observations. He had listened with great pleasure to the very interesting case which had just 
been read to the society, and coincided entirely with the remarks made by Dr Coldstream. He had paid some attention to the subject, and, along with Dr C., regretted to find that there was not a sufficiently minute and extensive record of these most remarkable cases to warrant any very confident and distinct conclusions. What struck him as particularly remarkable in the present case was the resistance, evidently dependant on mental apprehension, manifested by the patient to the introduction of food into the mouth. The very slightest touch of the spoon, it appeared, was sufficient to excite violent muscular motion, and proved clearly enough the existence of sensation in and around the lips; while yet, as Dr Coldstream stated, flies might traverse the lips and face in all directions without seemingly giving any annoyance, or, at any rate, eliciting any movement. Now, this seemed very analogous to certain other phenomena of more ordinary occurrence, and referable to a general law of consciousness, to which he would advert immediately. He could grope after an explanation of the anomalous circumstance in this state by supposing it most likely to be furnished by the general and striking fact that the mind may be perfectly alive and sensitive for an instant, and an instant only, to any impression $a b$ extra; while yet a patient may possibly acquire by habit and settled determination of will the power of so instantly and entirely withdrawing attention as to be unable, almost the next moment perhaps, to remember that any sensation had been felt at all. The present case, however, was evidently very complicated. We had sensibility to bodily impressions, and, at the same time, such a power of mental abstraction, or some other condition of equivalent effect, that these impressions ceased to be followed by their usual physical consequences, which he was strongly inclined to suppose referable, in part at least, to a transient exercise of voluntary power. The law to which he had already referred was that of latent mental modifications. Leibnitz and others held that changes were continually going on in the mind beneath the level of consciousness, and which only in mass, or in their results, came up above the surface, so to speak, and revealed themselves to the mind's own observation. The doctrine in this form was not certainly without its difficulties; but none such appeared to attach to the very simple view which had been stated a moment ago. And just as we found in the case of the external senses, that a certain strength and duration of physical impression was indispensable for the production of sensation, so with regard to all mental modifications a law not very dissimilar might well be conceived to hold. namely, that a certain strength and duration of each was necessary, not, indeed, in order to its being felt at all, and at the very instant, but in order to its being capable of being recalled by the memory and being reflected upon, or being known to have ever existed. In both cases alike, attention or voluntary concentration of mental regards was of power, within certain limits, to do the work of greater time and intensity, while voluntary and energetic abstraction of the attention had the opposite effect of proportionally reducing and weakening. He was disposed to believe that this law had much to do with the explanation of at least part of the apparent insensibility in this case to particular physical impressions. Of course, the difficulty was still unexplained of the total absence of even reflex action in the muscles of the lips and face from the irritation of flies. If such action was really and purely reflex alone, and in no degree sensational, he could only confess his ignorance both of the precise state of body indicated thereby, and of the mode in which wish or purpose on the part of the patient could operate to produce it. On the other hand, so far as there was any reason to believe the action dependant upon sensation, the considerations adverted to might be not unimportant towards furnishing the explanation.

The President did not think that the peculiar symptoms which had been alluded to were connected with mind at all. In his opinion, they were rather of a reflex character ; they were very like a spinal action, and did not at all resemble a cerebral one. Similar observations had been made on persons suffering from tetanus. The cases on record of fotuses being born without brains, 
and yet in whom the action of sucking was performed on the mouth being touched, as well as the experiments of Grainger and others, in his opinion, conclusively showed that such movements as had been observed in the case related by Dr C. were not necessarily cerebral. It was difficult however, he allowed, to separate such reflex acts from mental ones. He thought it probable that had experiments been instituted in this case while the patient was either asleep or under the influence of chloroform, it might have been determined satisfactorily to which of the classes the movements belonged. It might be asked, if the acts were reflex, why the contact of the fly did not excite them as well as the spoon, the only reason he could give was the greater minuteness of the impression.

Cases of Disease of the heart giving Rise to Systolic murmur at the aPex, WITHOUT DEFORMITY OF THE MITRAL VALVE ; WITH REMARKS ON THE PROBABLE MECHANISM OF THE MURMUR IN SUCH CASES. BY W. T. GAIRDNER, M.D.

$\operatorname{Dr} G$. communicated a number of details with reference to the occurrence of systolic murmurs at the apex of the heart in cases in which no valvular deformity existed, and where it was presumed that regurgitation through the auriculo-ventricular orifices must have been caused by dilatation of the ventricles rendering the valves incompetent. Dr G. remarked that cases of this kind had been recorded by various observers, but that in most of them the regurgitation was ascribed to a dilated condition of the orifice, and considered as a rather rare and exceptional condition. He believed it to be, on the contrary, one of the usual consequences of a certain amount of ventricular dilatation; but reserved for a future occasion the discussion of the mechanism of the auriculo-ventricular valves on which it depended. The views of Lænnec, Hope, Stokes, and other authors, as to the systolic apex-murmurs were adverted to, and the importance of the entire subject with regard to cardiac pathology, diagnosis, and treatment was pointed out.

The President suggested that the murmurs which Dr Gairdner brought under the notice of the society might be due to vibrations in the blood in its passage through the auricle.

After a few remarks from Drs W. Begbie and Gairdner, the society adjourned.

MR BLACKLOCK ON THE CHOLERA IN DUMFRIES.

\section{(To the Editor of the Monthly Journal of Medical Science.)}

Sir,--In reply to Dr Grieve's letter to you of the 14th ult., stating that he had perused with much interest my observations on the origin of cholera in Dumfries, and regretting that I had confined my remarks to the origin of cholera only, and had not favoured you with my sentiments on the nature and treatment of it, I beg leave to say that the sole object I had in view when I addressed you on the 13th Feb. last, was to rectify the mistake which Dr Grieve unfortunately committed when he declared that the next or early cases of cholera, did not appear here in the autumn of 1832 , in the same locality in which the first case appeared. This being quite at variance not only with the records of our local Board of Health, but also with my own private notes and memoranda, and distinct remembrance of almost every circumstance of any importance connected with the outbreak of the disease on that occasion, I considered it my duty to endeavour, with as little delay as possible, to remove all misunderstanding on the subject, more especially as I was anxious, and always have been, that our statistics of cholera should be carefully preserved, and that nothing hastily or inconsiderately asserted, should be permitted to remain uncontradicted, if it have the slightest tendency to mar or defeat the great object we must all have in view, the prevention of the pestilence. Dr Grieve, however, I am glad to find, now admits that the first five or six cases of cholera did occur in English Street. The remarks in my former letter were chiefly confined to the progress of the cholera during the first seven or eight days of the epidemic here in 1832 ; and I still adhere to what I then stated, with the trifling 
exception that the case mentioned by me as having occurred in the Globe Inn Close, did not occur there but in Herries' Close ; although this, to say the most of it, is a distinction without a difference, for these Closes run parallel to, and communicate with each other; Herries' Close being a few paces nearer English Street than the Globe Inn Close. Dr Grieve says that Callan, the patient, lodged in Queensberry Street, and was known to be lahouring under choleraic diarrhœa, when he went thither in the morning. This last circumstance is not unlikely, for the most of the attacks of cholera at that time were preceded by diarrhœa, although the man told me, in the presence of Dr. Charles Bell, after being removed to the cholera hospital, that he was quite well when he left home in the morning; and on being questioned as to what he had been eating and dinking, he replied that he had eaten little or nothing, but that he had taken, as he was in the habit of doing, one glass of whisky on his way to the workshop. That part of Queensberry Street, however, in which Callan lodged, communicates by three filthy lanes (in one of which his abode was situated) with Flesh Market Street, near to where it terminates in that part of English Street, in which the first five cases of cholera appeared, so that his place of abode was really much nearer the origin of the disease than either the Globe Inn Close or Herries' Close. But, as Dr. Grieve thinks that my information cannot be implicitly relied upon, as it is derived from the minutes of our local Boards of Health in 1832 and 1848, I must take this opportunity to state, that in 1832 , the sederunt or minute-book of the local hoard of health, of which the late Mr M.Lauchlan and myself were the medical members, was carefully kept by our active and zealous secretary, $\mathrm{Mr}$ Gemmill, and few or no mistakes of any importance were committed. Indeed, during the first week of our visitation of cholera in 1832, to which my former letter referred, I am perfectly satisfied that the only case not recorded was Barnaghan's, for at that time, there was neither excitement nor panic in this place, as alleged by Dr Grieve, and the number of resident medical practitioners was more than sufficient for the calls that were made upon them. ${ }^{1}$ There were thirteen of us, all of whom, with the exception of the late Dr Maxwell, who was far advanced in life, were both willing and able to take charge of any case of cholera that might appear; and, as not more than nine cases did appear in the course of the first week, I think you will agree with me that, up to the end of the seventh day, none of us were over worked. Mr M'Lauchlan and myself, being members of the Board, were almost constantly acting together at that time, acquiring information, and making the necessary arrangements for the treatment of the sick poor; and I am convinced that no case of cholera occurred during the first week of the epidemic, without our being apprized of it. It was not until nearly the end of the second week of the outbreak of the disease that the inhabitants became alarmed. On Wednesday, 26th September, one of our great annual fairs was held, and although the influx of strangers was not so large as on former occasions, yet there was a considerable attendance of people from the surrounding country; and during that night and the following day a very sudden and unexpected increase of attacks took place; and then, indeed, but not till then, we were running to and fro, and supplicating aid from a distance. As to the list of cholera patients kept by the Parochial Board here during the epidemic of 1848 - for at that time we had no local Board of Health-I perfectly agree with Dr Grieve that it is a document of little or no value ; and, for that reason, I refrained from making any further use of it than to copy the dates and locality of the first two cases of cholera which appeared on that occasion. But, when he states that no consistent plan of superintendence was organised until the arrival of Dr Sutherland, the Government inspector, he is altogether wrong;

1 Since writing this letter Mr Gemmill has kindly shown me that Barnaghan's case, and also Robert Hume's recovery, referred to by Dr Grieve, although not mentioned in the minute-book, are both fully recorded in the Board's list of cholera attacks, so that there is every reason to believe that no mistake whatever occurred during the first week.

NEW SERIES.-NO. LIII. MAY 1854. 
and to satisfy you as to this, I beg to call your attention to the enclosed printed copy of a letter, which was addressed to Dr Sutherland immediately on his arriving here, to which Dr Grieve's own name, and the names of six other resident medical practitioners, are affixed. By that letter you will perceive that this town had not only been divided into nine districts, previous to the arrival of Dr Sutherland, but that Dr Grieve himself took charge of one of them from the 24 th till the 30 th November, when the whole arrangement was cancelled by the sapient Board. Dr Sutherland, however, so soon as he was made acquainted with our previous arrangements, and the conduct of the Board, and with my plan of house to house visitation in each district, by qualified medical practitioners, known to the people, instead of by laymen, or medical students, as had been attempted in some places-for the purpose of ferretting out, and treating cases of diarrhœa, and of cholera in the earliest stages-he lost no time in intimating to the Board, that "the state of the town was most alarming, and that, if the original arrangement had been adhered to with the medical men, he had no doubt, from the skill with which their duty had been performed, that the disease would have been manageable," and added, "that he thought it requisite that the original division of the town into nine districts should be resorted to; and that a medical man of experience in cholera, and, if possible, acquainted with the localities, should be appointed to each, with an assistant." Of course, whatever Dr Sutherland thought requisite was a law to the Board ; for they were well aware that he had power to enforce what he advised ; consequently, all was speedily again in efficient order, and the result was most gratifying. I have not been thus prolix merely for the purpose of convincirig Dr Grieve, or any other person who may doubt the fact, that not more than nine cases of cholera appeared in this town during the first week of the fearful epidemic in 1832 ; for it certainly rests with those who entertain any doubt on the subject, to prove the opposite, by mentioning the names and abodes of the persons attacked; nor to prevent any one from being led to believe that no arrangement was made previous to the arrival of Dr Sutherland, for the treatment of the sick in 1848 ; but rather as a preparatory step to some observations on the origin and prevention of cholera in this country, which I may, perhaps, at no distant period, humbly submit to the profession.

Dr Grieve, like many others, strives to maintain the generally received opinion-which was also for many years my own opinion-that the malignant, or Asiatic cholera, is not, under any circumstances, contagious, or in any way communicable from person to person; for, when he tells us that during both our epidemic visitations some of the inhabitants of this town, who fled to Annan with the disease upon them, did not communicate it to any person there, he strangely forgets to mention what happened at Clarencefield; a fine, clean, well-aired, healthy village, delightfully situated, about nine miles from Dumfries, on the old Annan road; that while the cholera prevailed here in the beginning of winter, 1848, a postman, or runner, as he was usually called, who resided in that village, and visited Dumfries three times a-week, was seized by the disease, and sent for Mr Smith, a medical gentleman in that neighbourhood, who obeyed the summons, and carefully attended him until life was extinct. A woman, who acted as nurse on the occasion, and afterwards washed the postman's clothes, was then attacked, and soon died. Mr Smith also attended her ; and she was the last patient of any kind that he ever visited, for previous to leaving her he was himself attacked with cholera, and had to be conveyed home; and so rapidly did the disease run its course, that in three hours from the time he left his dying patient at Clarencefield, he was himself a corpse. The nurse had not been near Dumfries, nor any other infected place; and Mr Smith had not been within six miles of us. He had shortly before, however, attended a fisherman at Caerlaverock, six miles from this town, and likewise a man about a mile from Clarencefield, both of whom were attacked with cholera, and died, soon after returning from Dumfries. 
Now, it may be asked, were Mr. Smith and the nurse infected by the cholerapoison issuing from the postman's clothes, after they had been exposed upon his person to a pure uninfected atmosphere, at least three hours, while he walked from Dunfries to Clarencefield? or were Mr Smith and the nurse infected by a poison generated in, and emitted from, the postman's body ? If they were infected in the first way, no person, it is plain, should be permitted to come from an infected locality, unless he come in as naked a state as he came into the world! Medical men, and all others, who visit cholera patients in the infected localities, should likewise be obliged to change their clothes before visiting patients of any other description, in healthy localities. Notwithstanding, however, this Clarencefield event, and many similar occurrences, I am well aware that some more powerful influence than human emanations is concerned in the propagation of cholera; but what that influence, or primary cause is, we have yet to learn. We should not shut our eyes, however, to the well-established fact, that several diseases spread both by an epidemic influence and by human infection, and are often introduced in the latter way to localities where an epidemic influence does not exist. What reason, therefore, have we to suppose that the Asiatic cholera cannot also be communicated, or conveyed, in both ways? Indeed, the many well-authenticated facts which have been published since the first outbreak of cholera in the United Kingdom, place this beyond a doubt. ${ }^{1}$ And who can now pretend to say, when cholera prevails in a populous district, how much the spread of the disease is caused by emanations from the sick, and how much by the epidemic influence; or how far a combination of both hurries on the destructive march of the pestilence? Opinions, it has been well observed, are of two kinds, those founded on facts and reasoning; and those hazarded without a knowledge of either; and that rational opinions must undergo modifications with the facts from which they flow.-I am, etc. etc.

Archd. Blacklock.

CANCEROUS ULCER OF THE THIGH.

\section{(To the Editor of the Monthly Journal of Medical Science.)}

SIR,-My attention has just been called to a notice in the British and Foreign Quarterly Review for January 1854, page 281, in which a case is quoted from the Monthly Journal of Nov. 1853, p. 413, which is described "as a very satisfactory amputation of the thigh " for " a malignant ulcer," and it goes on to state, that with the exception of a slight tendency of the posterior flap to retract, reported on the seventh day, nothing occurred to interrupt the cure, which was complete in about nine weeks.

As the patient has since died from a return of malignant disease in the stump, I am induced to give the sequel of the case to correct what would otherwise prove a statistical error, should this case find its way into a table of successful operations for the cure of malignant disease.

I saw the patient a few days after his return from Scotland, when I found the wound healed with the exception of a small surface about the size of a fourpenny piece in the line of the union of the flaps. This wound gradually increased, considerable tumefaction of the stump followed, and he complained of great pain. There was a very considerable amount of purulent discharge from the wound, and in a week or two the ulcer had increased to about half its original size, and the ulcer put on precisely the same characteristic appearance as the original disease.

The discharge continued to increase, and the patient gradually sunk, and

1 I beg to refer you to a letter from the late amiable and highly-gifted Mr Moir of Musselburgh, dated March 2, 1849, and addressed to my respected friend, Mr Scot of Craigmuie, late Secretary of the Medical Board of Madras, contained in the Introductory Remarks to the abridged edition of his Report on the Epidemic Cholera, as it appeared in the territories subject to the Presidency of Fort St George, drawn up by order of Government, under the superintendence of the Medical Board Published by Blackwood and Sons, Edinburgh, and Murray, London. 1849. 
ultimately died on the 24th January 1854, just six months after the operation. For a short time it was doubtful whether the pain, tumefaction, and discharge might not have resulted from the irritation of carious bone in the stump, but afterwards the appearance and characters of the sore left no doubt on my mind that it was a return of the original disease. The patient was under my care for some months previous to his visit to Edinburgh, and was seen by Mr Bickersteth and his son. We did not advise amputation. Indeed I scarcely think the idea occurred to any of us. It certainly was not mentioned in consultation, and the result of the case has not been such as to make me regret the view we took ; at the same time, if the patient chose to take the alternative, it was, perhaps, just worth while to give him the chance. As it has turned out, I question very much whether life was at all prolonged, or his sufferings diminished, by the temporary removal of the disease, for he did not, while under my care, suffer very much from pain, nor did the ulceration proceed rapidly. I was unable to obtain permission to examine the parts after death, but I suspect the interior of the stumpars estensively occupied by malignant disease.-Your obedient Servant,

Liverpoor, April 17, 1854.

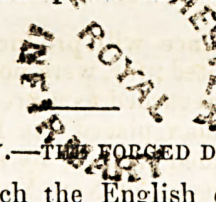

\section{A. B. Steele, M.R.C.S.}

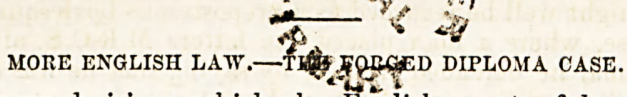

The extraordinary decisions which the English courts of law so frequently present us with, when the subject of them in any way relates to the medical profession, is one of the greatest anomalies of the age. In most civilised nations a medical practitioner is obliged to hold a diploma, which indicates that he has been educated for the profession, or that his competency has been tested by an examination, and he who falsely assumes the title of doctor or surgeon is visited with summary punishment. Again, in most codes of law, culpable hornicide is a crime ; but what is culpable homicide, if it be not destroying life by administering powerful drugs, when unacquainted with their properties? Yet such is the absurdity of English law, that it has been proved over and over again, that if, for the purpose of gain, a deadly poison be so administered as to cause death, and the individual prescribing it plead ignorance of medicine, both judge and jury consider there is no harm done. But if a regularly educated medical practitioner commit a mistake, heavy damages are awarded, and should malpraxis be followed by death, it is with the utmost difficulty he can escape the penalty of manslaughter. The result to be deduced from this state of things is obviously that it is safer in the eye of English law to be ignorant than skilful, to impose on the public than serve them faithfully, to practise the grossest quackery than exercise one's profession honourably. Need we be surprised that Charlatanism under such circumstances should flourish, and that the public should at length look with indulgence on crimes which are not only not repressed, but are positively encouraged by the State.

Another singulai illustration of this state of things has lately occurred. An individual named Lewis Bossy represents himself as an M.D. of the University of Edinburgh, and hangs up a forged diploma in his surgery, to impose upon all and sundry. In this capacity, among other things, he does not hesitate to sign schedules of individuals applying to insurance companies, whose lives are insured on the faith of his representations. The validity of these insurances is, we believe, to be made the subject of another trial, and the mischief he may have occasioned in this way is yet to be ascertained. But this impostor, on the 8th ultimo, was tried at the Central Criminal Court in London for a misdemeanour, he " having uttered as true a false diploma of Edinburgh, entitling him to practise and assume the title of "Doctor of Medicine." The offence was distinctly proved; and " the jury, after a little hesitation, returned a verdict of Guilty, but with a strong recommendation to the merciful consideration of the Court"! Whereupon the Judge (Mr Baron Martin) gives utterance to 
the following sage and indisputable remarks :- "It was undoubtedly an offence to utter a diploma like this, and persons should understand that if such a document was hung up in their houses where patients might see it, it was an uttering in law, and rendered them liable to the consequences. He could conceive cases where very great mischief might arise from an individual holding himself out falsely to be a physician. No man ought to trade upon a false bottom ; and, undoubtedly, the fact of a person professing to have a diploma from the University of Edinburgh, where it was known that a very severe examination had to be undergone, was calculated to give a man a position, and create a confidence, which no man ought to possess unless he was really entitled to it."

The learned Judge is then reported to have passed sentence upon this man who he could conceive might, by his gross fraud, commit great mischief, in the following terms :- "It was his intention on the present occasion merely to pass a nominal sentence, which was one of two days' imprisonment; and the defendant under that sentence would be entitled to his immediate discharge; but he hoped that the present proceeding would have the effect of putting a stop to such practices in future."

Whether such a heavy sentence will produce the effect the learned Judge anticipates may be much doubted; for, were not the whole proceeding a melancholy truth, it might well be regarded as a preposterous burlesque.

In another case, where a man placed the letters M.R.C.S. after his name, without a diploma, he defended limself by saying that he was a Member of the Reformed College of Surgeons, of New York !

\section{MEDICAL REFORM. THE ASSOCIATION BILL.}

THE time is now approaching when every medical man who truly loves his profession, ought seriously to consider the question of medical reform. On the 10th ultimo, Lord Palmerston said, in the House of Commons, that he had received so many complaints and objections against Mr Brady's bill, that he should consider it to be his duty to resist its further progress. He added, that the question of registration would naturally form part of a general measure, and that he had under consideration the bill of the Provincial Medical Association. This, then, is the only measure which we are now called upon to criticise, and we trust it has already been conclusively shown, that for one of the great ends for which a medical reform is required, namely, equality of privilege throughout the kingdom, it is worse than useless. A conference, we are informed, was held by delegates from all the medical bodies on Tuesday the 25th ultimo, in the hall of the London College of Physicians, the result of which had not reached us on going to press.

In addition to the utter alssence of provisions for securing equality of privilege throughout the kingdom, which must secure the failure of the Association Bill as we now have it before us, it is further objectionable from the unnecessary complexity of its plan. There are to be three councils, an English, Scotch, and Irish one, Why not one council, if uniformity be sincerely desired? And if the idea of centralization in the metropolis be objected to, let such council meet in London, Edinburgh, and Dublin in turn. Great care should be taken that the council be sufficiently large, and formed on such a liberal basis as to place it above the suspicion of interested views. According to this Association Bill, each council is to appoint a board of examiners, to license for practice, the result of which will be, that such licence will be considered, as a matter of course, the truly essential one. Indeed, this is also secured by the bill, as no one is to be allowed to register without it, and in consequence, all the present boards will be rendered useless, and many institutions ruined. Yet there are no provisions for securing, that an examining board, so mischievous in its effects, will be in any degree superior to those which already exist.

We hope, however, that the Association Bill may be considerably changed as a result of the conference, and we forbear from making further comments on the matter at present. But should a modified bill reach us sufficiently 
early, we shall dedicate an article to an exposition of the political and social state of the profession in our next number.

PROFESSOR JAMESON.

Tris distinguished individual expired on the 19th ultimo, aged 81 years. He occupied the Chair of Natural History in this University for half a century, and may be called the father of modern natural history in Scotland. The science had flourished under Sir Robert Sibbald and his contemporaries, but had sunk to the lowest ebb when it received new vigour from the labours of Mr Jameson. The magnificent museum which now fills our halls and galleries to overflowing, is mainly indebted to him for its existence and present excellence. As a teacher, he especially possessed the art of exciting enthusiasm in his pupils; and those who attended his practical demonstrations and excursions in the country, will not easily forget the interest and indelible impression they produced on the mind. As a writer and journalist, he may be regarded as the principal means by which the mineralogy and geology of Scotland have been made known during the last half century.

We have found it impossible, however, to do justice to the life, character, and scientific eminence of Professor Jameson in the short space which has intervened between his death and the period of our going to press. We propose giving a biographical sketch of him in our next number, and shall feel obliged to any of our readers who can furnish us with available facts and information for its compilation.

\section{VARIETIES.}

War and Pestilence.-Some interesting tables have issued from the Health Office, comparing the loss of life by war and pestilence. It appears that in twenty-two years of war there were 19,796 killed, and 79,709 wounded, giving an annual average of 899 killed and 3623 wounded. In 1848.49, there were no fewer than 72,180 persons killed by cholera and diarrhœa in England and Wales, and 144,360 attacked ; 34,397 of the killed were able-bodied persons capable of getting their own living! Besides these deaths from the great epidemic, 115,000 die annually, on an average, of preventible diseases; while 11,419 die by violence. Comparing the killed in nine great battles, including Waterloo-4740 - with the number killed by cholera in London in 1848-4914,139-we find the difference of 9399 in favour of war. In cholera visitations, 12 per cent., sometimes 20 per cent. of the medical men employed, died. The London missionaries die as fast as those in foreign countries, and there are some districts in London which make the Mission Society ask themselves whether they have a right to send men into them. From the returns of twelve Unions it is found that 3567 widows and orphans are chargeable to the cholera of 1848-49, entailing an expenditure of L.121,000 in four years only.-Edinburgh Advertiser.

The War against the Lancet.-The Council of the Medico-Chirurgical Society has decided on retaining this Journal, although a memorial in its favour was supported by only 104 menbers, whilst the opposition one had appended to it 155 names. Hence the Lancet has gained the first battle with inferior numbers, but tarnished its victory by immediately afterwards proceeding to slaughter the character of the enemy's General. This has given rise to loud murmurs, and greatly exasperated the rebel army. The conspirators have lately been reinforced by the Reading Pathological Society, and are actively engaged in reorganizing their ranks with a view to another battle. They loudly assert that the advantage in the last action was obtained more by stratagem and false pretences than by fair fighting. The Lancet, on the other hand, strongly entrenched among the Council, and ably supported by its powerful allies, President Copland and Sir Benjamin Brodie, makes from time to time murderous sallies into the hostile camp. Both parties feel confident of ultimate success, and we look with the most intense anxiety for the next intelligence from the seat of war. 
Development of Tapeworms.-M. Von Bunsen has written to the Academie des Sciences, that a pig who swallowed at the end of last October some eggs of the Tornia solium, passed by a woman, was lately killed, and a large number of cysticerci were found in its muscles.-Gazette des Hosp., 13 Avr?l. This may have been a coincidence, as it is not mentioned that the nuscles of the animal had been examined before the commencement of the experiment.

The Medical Commission at Bucharest.-Dr Cuillat informs us that at Bucharest there is a medical commission charged to examine the diplomas and medical knowledge of all the foreign medical men who come to practise there. He himself, notwithstanding his title of doctor, and certificate as an interne of the French hospitals, was conducted to the Coltza hospital, and requested to examine two patients, which having done, and satisfactorily determined their diseases, indicated the appropriate treatment, etc., he was authorised to practice. $\mathrm{He}$ attributes this unaccustomed favour to the advantages he received as an interne, which enabled him to acquit himself well at the bed side. Generally speaking, the holders of French and English diplomas are remitted by this commission for another six months, on account of insufficient knowledge of medical practice.-Gazette des Hopitaux. From this account, it would appear that medical examinations are much better performed in Wallachia than they are among us.

Alleged Cruelty to the Wounded in Naval Warfare.-In the article on "Wounds" in the Encyclopædia Britannica, 4th edition, published 1810, the author, after mentioning the necessity of a surgeon being cautious in pronouncing on the character of any wound, adds that "this is particularly necessary on board ship, where, as soon as any man is pronounced by the surgeon to be mortally wounded, he is forthwith, while still living and conscious, thrown overboard ;" or words to that effect. This statement is untrue; for Smollett and other writers, who have exposed with unsparing hand all the defects in the naval system of their day, would have scarcely left this unnoticed, when they attack much slighter abuses. If such a thing ever occurred, even in the worst of times, it must have been an isolated case.-Notes and Queries.

Shaving.- It is in vain to urge that shaving is a nuisance. Every one admits the fact, but no one is ready to forego the infliction. The dread of being thought odd, peculiar, and eccentric, is too much even for the wisest of men to overcome. A learned lady once deplored the misfortune of her sex, and the heavy weight of that primæval curse which declared that "in sorrow woman should bring forth children." "Ah, madam!" said a still more learned person in reply, "bewail your fate no more : the evil you lament is not of frequent occurrence, and does not afflict old age. Think of man's misery, who has to shave every day : you may then decide whose afflictions are the greatest." "But man's are self-imposed," said the lady; and the philosopher was silenced. - Illustrated London News.

Difficulty of introducing pure air into the House of Commons.-On the 10th ultimo, Mr Spooner made some startling statements to the House of Commons concerning ventilation. It would seem that the nation in its anxiety to preserve the lungs of the 650 gentlemen who legislate there, has paid no less a sum than L.250,000. And yet all the members concur in saying that this costly attempt at ventilation is a perfect failure. The quarter of a million has been literally scattered to the four winds of heaven, for not one of them can be induced to cross the threshold of the House.-Glasgow Commonwealth.

Monsieur Roux.-This distinguished surgeon died on the 24th of last March of apoplexy, at the age of 73 . He entered the army when 15 years old, in 1797, as a surgeon of the third class, and served two years. He then studied in Paris, and in 1802 succeeded Bichat as teacher of anatomy. For the last 30 years, he has been regarded as one of the first practitioners in Paris, and on the death of Dupuytren became the senior surgeon of the Hotel Dieu. 
Chair of Natural History. - The Town Council of Edinburgh have unanimously memorialised the crown to present Professor Edward Forbes to the chair, vacant by the death of Professor Jamieson. This course, though not unprecedented, is very unusual, and we trust will have due influence with the government.

Medical Organization in Algeria.-The French government has divided all the colonised territories of Algeria into departments, to each of which a medical man is appointed, under the name of Médicin de Colonization. His salary is 2000 francs (L.80) per annum, and if required to be mounted he receives 500 franes (L.20) in addition.- Journal de Méd.

Radical Cure of Inguinal Hernia.-On the 2sth of last March M. Jobert (de Lamballe) presented a patient to the Academy of Medicine in whom he had produced a radical cure of inguinal hernia, by puncturing the sac and injecting iodine, which, by occasioning adhesive inflammation, had caused permanent obliteration of the sac.-Gazette des Hopitaux.

Election of M. Claude Bernard as Professor of General Pitysiology. -A new chair of General Physiology has been created in the Faculty of Sciences at Paris, to which M. Claude Bernard has been appointed. The course will extend over two years, and be given only during the summer session at the Sorbonne.

Medical Menbers of the Legion of Honour.-The member's of the Legion of Honour amount in all to 52,709 . Of these there are 1850 medical men, thus divided :-Military, 867 ; naval, 233 ; civil, 750 ; military and naval apothecaries, 109 ; civil apothecaries, 29.-Gaz. des Hop.

Professor SKoda has presented to the charitable institution for supporting students when unwell the sum received for the fifth edition of his work on auscultation and percussion-namely, 3000 florins.-Allgemiene Medic. Centr. Zeit.

\section{PUBLICATIONS RECEIVED.}

A Treatise on Acute and Chronic Diseases of the Neck of the Uterus. Illustrated with numerous plates, coloured and plain. By Charles D. Meigs., M D., Professor of Midwifery, and the Diseases of Women and Chilitren in Jefferson Medical College, etc. Philadelphia and London. 8vo. 1854. Pp. 116.

An Inquiry into the Pathological Importance of Ulceration of the Os Uteri, being the Croonian Lectures for the year 1854 . By Charles West, M.D., Physician-Accoucheur to St Bartholomew's Hospital, etc. London. 8vo. 1854. Pp. 95.

On the Use of an Artificial Membrana Tympani in Cases of Deafness, dependant upon Perforation or Destruction of the Natural Organ. By Joseph Toynbee. F.R.S., Aural Surgeon to St Mary's Hospital, etc. Second edition. London. 1854. 8vo. Pp. 32.

Cyclopædia of Chemistry, with its Applications to Mineralogy, Physiology, and the Arts. By Robert Dundas Thomson, M.D., Professor of Chemistry in St Thomas' College, London, etc. With numerous Illustrations. London and Glasgow. 1854. 8vo.

The papers of Drs Peddie, George Paterson, Lindsay, Skae, and Alexander, will be inserted as early as possible.

We have been under the necessity of postponing the conclusion of Stokes on the Heart, with numerous other Reviews, and much Periscopic matter.
Dissertatio anatomica inauguralis de cerebri et medullæ spinalis systemate vasorum capillari in statu sano et morboso, etc. eruditorum examini submittit Everardus Henricus Ekker Rheno-'Trajectinus. Trajecti ad Rhenum. 1853. 8vo. Pp. 120.

Over de vorming en verspreiding van kankercellen in dem omtrek van kanker en het gewigt hiervan bij. het doen eener operatie. Door J. L. C. Schroeder van der Kolk. Utrecht. 8vo. Pp. 30.

Archives de Physiologie de Therapeutique et d' hygiéne sous la direction de $\mathbf{M}$. Bouchardat, Professor d' hyuriéne à la Faculté de Médicine de Paris. No. I. et la Digitale. Par E. Homolle et T. A. Quevenne. Paris. 1854. 8vo. Pp. 376.

Notes on the Pathology and Treatment of Cholera. By John Rose Cormack, M.D., Edinburgh, etc. London. 1854. $12 \mathrm{mo}$. Pp. 67.

A Letter to the Right Hon. the Earl of Grauville on the importance of rational Gymnasties, as a branch of National Education, etc. By M. Roth, M.D. London. 1854. 8vo. Pр. 39. Janvier 1854. Mémoire sur la Digitaline 